\title{
Mechanical efficiency of high versus moderate intensity aerobic exercise in coronary heart disease patients: A randomized clinical trial
}

\author{
Koldobika Villelabeitia-Jaureguizar ${ }^{1}$, Davinia Vicente Campos ${ }^{2}$, \\ Alejandro Berenguel Senen ${ }^{3}$, Verónica Hernández Jiménez $z^{4}$, Lorena Ruiz Bautista ${ }^{4}$, \\ María Elvira Barrios Garrido-Lestache ${ }^{4}$, Jose López Chicharro ${ }^{5}$ \\ ${ }^{1}$ Infanta Elena University Hospital, Valdemoro, Madrid, Spain \\ ${ }^{2}$ Facultad de Ciencias de la Salud, Universidad Francisco de Vitoria, UFV, Polideportivo, Ctra. M-515 \\ Pozuelo-Majadahonda km.1,800, 28223 Pozuelo de Alarcón, Madrid, Spain \\ ${ }^{3}$ Virgen de la Salud University Hospital, Toledo, Castilla La Mancha, Spain \\ ${ }^{4}$ Rey Juan Carlos University Hospital, Madrid, Spain \\ ${ }^{5}$ Grupo FEBIO, Universidad Complutense de Madrid, Spain
}

\begin{abstract}
Background: Mechanical efficiency (ME) refers to the ability of an individual to transfer energy consumed by external work. A decreased $M E$, could represent an increased energy cost during exercise and may, therefore, be limited in terms of physical activity. This study aimed to compare the influence of two different exercise protocols: moderate continuous training (MCT) versus high intensity interval training (HIIT), as part of a cardiac rehabilitation program on ME values among coronary patients. Methods: One hundred and ten coronary patients were assigned to either HIIT or MCT groups for 8 weeks. Incremental exercise tests in a cycle ergometer were performed to obtain $\mathrm{VO}_{2}$ peak. Net energy expenditure (EE) and $M E$ were obtained at intensities corresponding to the first $\left(V T_{1}\right)$ and second $\left(V T_{2}\right)$ ventilatory thresholds, and at $\mathrm{VO}_{2}$ peak.
\end{abstract}

Results: Both exercise programs significantly increase $V_{2}$ peak with a higher increase in the HIIT group $(2.96 \pm 2.33 \mathrm{~mL} / \mathrm{kg} / \mathrm{min} v \mathrm{~s} .3 .88 \pm 2.40 \mathrm{~mL} / \mathrm{kg} / \mathrm{min}$, for patients of the MCT and HIIT groups, respectively, $p<0.001)$. The $M E$ at $V \mathrm{O}_{2}$ peak and $V T_{2}$ only significantly increased in the HIIT group. At VT, ME significantly increased in both groups, with a greater increase in the HIIT group $(2.20 \pm$ $\pm 6.25 \%$ vs. $5.52 \pm 5.53 \%$, for patients of the MCT and HIIT groups, respectively, $p<0.001$ ).

Conclusions: The application of HIIT to patients with chronic ischemic heart disease of low risk resulted in a greater improvement in $V_{2}$ peak and in $M E$ at $V T_{1}$, than when MCT was applied. Moreover, only the application of HIIT brought about a significant increase in $\mathrm{ME}$ at $\mathrm{VT}_{2}$ and at $\mathrm{VO}_{2}$ peak. (Cardiol J 2019; 26, 2: 130-137)

Key words: coronary artery disease, cardiopulmonary exercise test, high interval training, mechanical efficiency, energy expenditure

\section{Introduction}

Mechanical efficiency (ME) refers to the ability of an individual to transfer energy consumed by external work. Most studies that assess the efficiency of the different cardiac rehabilitation exercise programs evaluate the modification of the cardiovascular risk factors, quality of life and clinical variables associated with the prognosis of morbidity and mortality (i.e. $\mathrm{VO}_{2}$ peak), but there

Address for correspondence: Koldobika Villelabeitia-Jaureguizar, MD, Infanta Elena University Hospital, Valdemoro, Madrid, Spain, tel: +0034 6460040 80, e-mail: koldovillelabeitia@hotmail.com 
is very little research that evaluates ME, even though it provides important information concerning biomechanical adaptations and the use of the energy sources associated with clinical training and therefore the functional capacity of patients.

A decreased ME, which indicates that more energy is consumed at a given work output, could represent an increased energy cost of breathing during exercise, an altered efficiency in ATP production (ATP produced per $\mathrm{O}_{2}$ consumed), or a higher ATP cost of contraction (ATP consumed per work output) [1]. Therefore, individuals with lower ME values should be less efficient in respect to performance and may therefore be limited in terms of physical activity [2]. Consequently, the evaluating ME may be valuable for the detection of muscle dysfunction and the assessment of any subsequent adaptations in response to training [3].

The results of a recent meta-analysis [4] have confirmed that the inclusion of exercise programs in cardiac rehabilitation reduces cardiovascular mortality and hospital readmissions in coronary artery disease $(\mathrm{CAD})$ patients. For many years moderate continuous training (MCT) has been accepted as the gold standard [5]. However, recent evidence suggests that high intensity interval training (HIIT) may be a better modality for the improvement of aerobic exercise capacity [6]. Recently, with CAD patients, a superiority has been demonstrated of HIIT over MCT with greater increases in $\mathrm{VO}_{2}$ peak, as well as the recuperation rates of post-exercise heart rate. This constitutes an emerging prognostic variable of heart disease [7, 8].

Several studies have demonstrated that HIIT results in significant increases in muscle performance in untrained males. These adaptations are likely the result of skeletal muscle adaptations related to metabolic improvement associated with strengthening of muscle. Given that metabolic environment and muscle function may condition muscle performance and muscle energy profile of an individual, it is possible that any improvement in these parameters may be predictive of a subsequent increase in ME [2]. Therefore, ME may also be an important predictor of efficacy and may provide relevant data regarding performance and energy use adaptations in response to training [2].

Studies in young adults and older individuals [3] have reported significant increases in $\mathrm{ME}$ in response to HIIT. Considering that HIIT demonstrated a multitude of physiological adaptations that were correlated with performance and health benefits $[9,10]$, it was hypothesized that this form of exercise may promote greater improvements in $\mathrm{ME}$ among $\mathrm{CAD}$ patients.
This study aimed to compare the influence of two different exercise protocols (MCT vs. HIIT) as part of a cardiac rehabilitation program on $\mathrm{ME}$ values among coronary patients.

\section{Methods}

\section{Study population}

This is a unicentric, prospective and randomized clinical trial in patients with stable $\mathrm{CAD}$, which was registered on clinicaltrials.gov (NCT02168712). All patients underwent exercise testing with a cycle ergometer including analysis of exhaled gases.

The main study inclusion criteria were: 1) Stable New York Heart Association functional class I or II CAD with angina pectoris or myocardial infarction and no heart failure; 2) No change in medication during the study; 3 ) Included between 6 and 12 weeks following the cardiac event, elective percutaneous coronary intervention, or coronary artery bypass grafting; 4) Achieve the first $\left(\mathrm{VT}_{1}\right)$ and second $\left(\mathrm{VT}_{2}\right)$ ventilatory thresholds in the initial and final (cardiopulmonary exercise test [CPET]) and 5) Achieve a respiratory exchange ratio $\geq 1.10$ in both CPET. Patients who had residual ischemia (by electrocardiogram criteria or angina symptoms), severe ventricular arrhythmias, uncontrolled hypertension, permanent pacemakers, or implanted cardiac defibrillators were excluded.

Patients were randomized on a one-to-one basis to either the MCT or the HIIT group. The mode of exercise training was a cycle ergometer with 40 min per session, 3 days per week (total of 24 sessions over 2 months).

Selected CPET variables and ME measurement were recorded before and after the exercise program. ME (expressed as a percentage) was calculated during an incremental maximal cycling test at stages corresponding to $\mathrm{VT}_{1}, \mathrm{VT}_{2}$ and $\mathrm{VO}_{2}$ peak. CPET were administered by staff who were unaware of the exercise training group the patients were assigned.

The study complies with the Declaration of Helsinki and was approved by the Local Ethics Committees, and written informed consent was obtained from each participant.

Characteristics and medication use of the patients are shown in Table 1.

\section{Cardiopulmonary exercise test}

The test was performed on an electro-mechanically braked cycle ergometer (Ergoline900S). The cycling position, which is known to affect 
Table 1. Patient characteristics and medication use.

\begin{tabular}{|c|c|c|c|}
\hline & MCT (n = 53) & HIIT (n = 57) & $\mathbf{P}$ \\
\hline Age [years] & $58.3 \pm 9.5$ & $57.6 \pm 9.8$ & 0.752 \\
\hline Men & $42(79.2 \%)$ & $50(87.7 \%)$ & 0.234 \\
\hline Body mass index $\left[\mathrm{kg} / \mathrm{m}^{2}\right]$ & $27.8 \pm 3.7$ & $29.1 \pm 3.9$ & 0.909 \\
\hline Waist circumference $[\mathrm{cm}]$ & $98.7 \pm 8.9$ & $101 \pm 14.3$ & 0.879 \\
\hline Hip circumference [cm] & $102.1 \pm 6.8$ & $103.5 \pm 8.1$ & 0.353 \\
\hline Cardiovascular risk factors: & $3.9 \%$ & $11.3 \%$ & \\
\hline Family history & $47.2 \%$ & $42.1 \%$ & 0.743 \\
\hline Hypertension & $47.1 \%$ & $49.1 \%$ & 1.000 \\
\hline Diabetes mellitus & $24.5 \%$ & $25.4 \%$ & 1.000 \\
\hline Dyslipidemia & $52.8 \%$ & $58.8 \%$ & 0.743 \\
\hline Smoking & $73.6 \%$ & $82.3 \%$ & 0.754 \\
\hline Stroke & $5.6 \%$ & $3.5 \%$ & 1.000 \\
\hline Peripheral vascular disease & $7.8 \%$ & $5.7 \%$ & 1.000 \\
\hline Hyperuricemia & $3.9 \%$ & $11.3 \%$ & 1.000 \\
\hline \multicolumn{4}{|l|}{ Heart disease factors: } \\
\hline LVEF [\%] & $60.3 \pm 9.7$ & $61.2 \pm 10.1$ & 0.622 \\
\hline \multicolumn{4}{|l|}{ Intervention: } \\
\hline Conservative & $9.4 \%$ & $8.8 \%$ & 1.000 \\
\hline $\mathrm{PCl}$ & $79.3 \%$ & $82.4 \%$ & 0.531 \\
\hline CABG & $11.3 \%$ & $8.7 \%$ & 0.429 \\
\hline Drugs administered: & $21.6 \%$ & $20.7 \%$ & \\
\hline Beta-blockers & $90.1 \%$ & $86.8 \%$ & 1.000 \\
\hline Calcium channel blockers & $13.2 \%$ & $19.3 \%$ & 0.684 \\
\hline ACE-inhibitors & $88.2 \%$ & $81.1 \%$ & 0.897 \\
\hline Angiotensin receptor antagonists & $17.6 \%$ & $16.9 \%$ & 1.000 \\
\hline Nitrates & $15.6 \%$ & $7.5 \%$ & 0.497 \\
\hline Antiplatelet agents & $97.3 \%$ & $97.4 \%$ & 1.000 \\
\hline Acenocoumarol & $9.4 \%$ & $5.4 \%$ & 0.596 \\
\hline Statins & $96.7 \%$ & $100.0 \%$ & 0.828 \\
\hline Ezetimibe & $5.6 \%$ & $5.3 \%$ & 1.000 \\
\hline Antidiabetics & $21.6 \%$ & $20.7 \%$ & 1.000 \\
\hline
\end{tabular}

ACE - angiotensin converting enzyme; CABG - coronary artery bypass graft; HIIT — high-intensity interval training; LVEF — left ventricular ejection fraction; $\mathrm{MCT}$ - moderate continuous training; $\mathrm{PCl}$ - percutaneous coronary intervention

energy expenditure, was standardized by adopting a top bar position. Saddle height was adjusted according to the participant's leg length and knee flexion was between 20 and 30 degrees. Toe-clips were used and participants were instructed to stay seated during the test. Patients were required to maintain a constant pedal cadence between 50 and 70 revolutions per minute.

An individualized exercise protocol was performed in all patients and was tailored to each patient's physical condition, with gradual increments of 10,15 , or $20 \mathrm{~W} / \mathrm{min}$. Required exercise time was between 6 and $12 \mathrm{~min}$ in order to respect the proper kinetics of oxygen consumption $\left(\mathrm{VO}_{2}\right)$ and to maintain a linear relationship between $\mathrm{VO}_{2}$, exercise workload and heart rate (HR) during CPET. The same protocol was applied before and after the exercise training program. Throughout the test, patients were kept under continuous 12-lead electrocardiographicmonitoring, and blood pressure was established every $3 \mathrm{~min}$.

$\mathrm{VO}_{2}$ was determined breath by breath using an automated system (UltimaCardiO2, Medical GraphicsCorporation, St. Paul, Minnesota, USA). The gas analysers were calibrated before each test. 
Table 2. Program designs for moderate continuous training (MCT) group or high intensity interval training (HIIT) group.

\begin{tabular}{|c|c|c|c|}
\hline Week & $\begin{array}{l}\text { Warm-up time and intensity } \\
\text { (MCT and HIIT) }\end{array}$ & $\begin{array}{l}\text { Exercise time } \\
\text { and intensity }\end{array}$ & $\begin{array}{l}\text { Cool-down time and intensity } \\
\text { (MCT and HIIT) }\end{array}$ \\
\hline 1 & 12 min (25 watts) & $\begin{array}{l}\text { MCT: } 15 \text { min at } \mathrm{VT}_{1} \\
\text { HIIT: } 15 \text { repetition }\left(^{*}\right)\end{array}$ & 13 min (25 watts) \\
\hline 2 & 10 min (25 watts) & $\begin{array}{l}\text { MCT: } 20 \text { min at } \mathrm{VT}_{1} \\
\text { HIIT: } 20 \text { repetition }\left(^{*}\right)\end{array}$ & 10 min (25 watts) \\
\hline 3 & 7 min (25 watts) & $\begin{array}{l}\text { MCT: } 25 \text { min at } \mathrm{VT}_{1} \\
\text { HIIT: } 25 \text { repetition }\left(^{*}\right)\end{array}$ & 8 min (25 watts) \\
\hline 4 & 5 min (25 watts) & $\begin{array}{l}\text { MCT: } 30 \text { min at } \mathrm{VT}_{1} \\
\text { HIIT: } 30 \text { repetition }\left(^{*}\right)\end{array}$ & 5 min (25 watts) \\
\hline $4-8$ & $5 \mathrm{~min}$ (25 watts) & $\begin{array}{c}\text { MCT: } 30 \text { min at } \mathrm{VT}_{1}+10 \% \\
\text { HIIT: } 30 \text { repetition }\left(^{* *}\right)\end{array}$ & 5 min (25 watts) \\
\hline
\end{tabular}

* 20 -second repetitions at $50 \%$ of the maximum load reached with the first steep ramp test (SRT) followed by 40 -second of recovery period at $10 \%$ of the first SRT; ${ }^{*} 20$-second repetitions at $50 \%$ of the maximum load reached with the second SRT followed by 40 -second of recovery period at $10 \%$ of the second SRT; $\mathrm{VT}_{1}$ - first ventilatory threshold

The $\mathrm{VT}_{1}$ and $\mathrm{VT}_{2}$ were determined following the method of ventilatory equivalents described by Skinner et al. [11]. $\mathrm{VT}_{1}$ corresponds to an increment of the $\mathrm{VE} / \mathrm{VO}_{2}$ ratio without an increased $\mathrm{VE} /$ $/ \mathrm{VCO}_{2}$ ratio, and with an increased concentration of oxygen fraction $\left(\mathrm{PetO}_{2}\right)$. $\mathrm{VT}_{2}$ corresponds to an increment of the $\mathrm{VE} / \mathrm{VCO}_{2}$ ratio and a fractional decrease in the concentration of $\mathrm{CO}_{2}\left(\mathrm{PetCO}_{2}\right)$.

\section{Training interventions}

MCT-Program Designs. To design the intensity prescription in MCT-program, the HR reached at $\mathrm{VT}_{1}$ were used and obtained during the pre-training CPET. During the second month, the intensity of the exercise was adjusted, increasing to a training HR that corresponded to $\mathrm{VT}_{1}$ plus $10 \%[7,8]$.

HIIT-Program Designs. To design the HIIT-program, the steep ramp test (SRT) protocol was used according to the methodology described by Meyer et al. [12] and described by the present work group in several articles $[7,8]$. The maximum exercise load achieved (watts), was the exercise parameter used to design the HIIT-program for each patient. In the first month of training, 20-s repetitions at an intensity corresponding to $50 \%$ of the maximum load reached with the SRT (peak intervals) were followed by 40 -s recovery periods at $10 \%$. In the second month of training, the intensity of exercise was adjusted using the results of a new SRT.

The total duration of both modalities of training was 40 min per session throughout the exercise program (including warm-up and cool-down). Table 2 summarizes the exercise time and intensity progression for both MCT and HIIT. Patients enrolled in the study participated in other activities established in this cardiac rehabilitation program that were aimed at managing psychological stress and learning about cardiac health habits. They were also taught to devise a home walking program for the days on which they did not have to attend sessions in the hospital. The recommended intensity of walking was a perceived exertion of 11 to 13 on the Börg Scale.

\section{Energy consumption and mechanical efficiency calculations}

$\mathrm{VO}_{2}$ net was obtained by subtracting resting $\mathrm{VO}_{2}$ from total $\mathrm{VO}_{2}$ at each exercise stage. The net energy expenditure (EE) in watts was calculated as follows [13]: $(4.94 \times \mathrm{RER}+16.04) \times\left(\mathrm{VO}_{2}\right.$ net, in $\mathrm{mL} / \mathrm{min}) \times 60^{-1}$. ME was also calculated in net terms as follows [14]: work produced in Watts $\times(\mathrm{EE}$ net, in $\left.\mathrm{Watts}^{-1}\right) \times 100^{-1}$. EE and ME were obtained at intensities corresponding to $\mathrm{VT}_{1}, \mathrm{VT}_{2}$ and at $\mathrm{VO}_{2}$ peak. This method allowed a comparison of these variables in terms of relative exercise intensity [3].

\section{Safety of the exercise training programs}

To verify the safety of using this kind of aerobic exercise training, a daily record was made of any incidents or adverse effects that could limit the planned exercise.

\section{Statistical analysis}

Quantitative variables were described using means and standard deviations. The normality of 
the data distribution was determined using the Kolmogorov-Smirnov test. To evaluate the effect of each exercise protocol on the quantitative variables, pre- and post-program values were compared using the Student dependent samples $t$-test. The effect was measured in absolute terms via the difference between the post-program values and those obtained before training. These changes were described with the mean and standard deviation. Comparisons between the two training programs were made using the Student $t$ test in the case of quantitative variables and using the $\chi^{2}$ test of association or Fisher exact test for qualitative variables. All comparisons were made using two-tailed tests, and the level of significance was set at $\mathrm{p}<0.05$. All statistical tests were performed using commercially available software (SPSS, Version 22.0, Inc., Chicago, IL, USA).

\section{Results}

A total of 110 patients were included and studied (53 patients in MCT-group and 57 patients in HIIT-group). At the start of the study, there were no significant differences between the groups with regard to clinical characteristics or medication use (as shown in Table 1).

\section{Training data}

The intensity of exercise in the MCT-group in the first month was $62.9 \% \pm 7.6 \%$ of the $\mathrm{VO}_{2}$ peak reached during the initial CPET (corresponding to the $\mathrm{VT}_{1}$ ) and $69.8 \% \pm 8.8 \%$ in the second month (corresponding to $\mathrm{VT}_{1}+10 \%$ ). The exercise workload applied at the peak intervals in the HIIT-group using the Meyer et al. [12] methodology was $108.3 \% \pm 20.7 \%$ (first month) and $126.1 \% \pm 27.8 \%$ (second month) of the maximum load reached in the initial CPET, corresponding to $50 \%$ of the SRT in the first and second month. The resulting HR during first and second month in HIIT-group was between $\mathrm{VT}_{1}$ and $\mathrm{VT}_{2}$.

\section{Cardiopulmonary exercise test}

The exercise effort test results for both groups can be seen in Table 3 . After 8 weeks of training both exercise programs significantly increased their $\mathrm{VO}_{2}$ peak, the peak exercise workload achieved and the total time of the exercise effort test with a greater increase in the HIIT-group $(\mathrm{p}<0.05)$.

The $\mathrm{VO}_{2}$ at $\mathrm{VT}_{1}$ and $\mathrm{VT}_{2}$ significantly increased in both groups, with a significantly higher increase in the HIIT-group ( $<<0.05)$. The power at $\mathrm{VT}_{1}$ significantly increased in both groups, with a greater increase in the HIIT-group ( $\mathrm{p}<0.01)$, but the power at $\mathrm{VT}_{2}$ only significantly increased in HIIT-group $(\mathrm{p}<0.001)$.

\section{Energy expenditure and mechanical efficiency values}

Energy expenditure determined at $\mathrm{VT}_{1}, \mathrm{VT}_{2}$ and at $\mathrm{VO}_{2}$ peak (Table 3 ) increased significantly post-training compared to baseline values in both groups but with a significantly higher increase in the HIIT-group.

Mechanical efficiency measured at $\mathrm{VT}_{1}, \mathrm{VT}_{2}$, and at $\mathrm{VO}_{2}$ peak is reported in Table 3. At $\mathrm{VT}_{1}$, ME significantly increased in both groups, with a greater increase in the HIIT-group $(\mathrm{p}<0.01)$. The $\mathrm{ME}$ at $\mathrm{VO}_{2}$ peak and $\mathrm{VT}_{2}$ only significantly increased in the HIIT-group $(\mathrm{p}<0.001)$.

\section{Safety of the training intervention}

No incidents or adverse events were recorded that limited the ability of patients to perform the prescribed exercise in either training program.

\section{Discussion}

According to available research, this study is the first to examine $\mathrm{ME}$ changes in response to 8 weeks of HIIT in patients with CAD. The most relevant finding of the present research was a greater increase in ME of the HIIT-group over MCT-group in intensities related to $\mathrm{VT}_{1}$, and a significant increase in the $\mathrm{ME}$ at $\mathrm{VO}_{2}$ peak and $\mathrm{VT}_{2}$ in the HIIT-group alone.

Exercise carried out at an intensity greater than $\mathrm{VT}_{2}$ necessitated an increase of energy contribution of the glycolytic pathway, even when oxidative energetic provision is predominant. Glycolytic activation disturbs the internal cell environment of the muscles involved in the exercise. This means that the mechanism of the excitement-contraction is negatively affected, progressively contributing to the onset of muscular fatigue. This process is related to the muscular capacity to work, and therefore negatively affects mechanical efficiency.

HIIT is a training system that has as its main objective the improvement of $\mathrm{VO}_{2}$ peak, but due to the relative high intensity which is applied $\left(>\mathrm{VT}_{2}\right)$, it is also the cause of improvements related to glycolytic metabolism in type II muscular fibres. This provides an improvement in energetic efficiency, in the development of strength and in resistance to fatigue, meaning an improvement in ME.

A relatively high cost of ATPs for muscular contraction is the main cause of the low ME ob- 


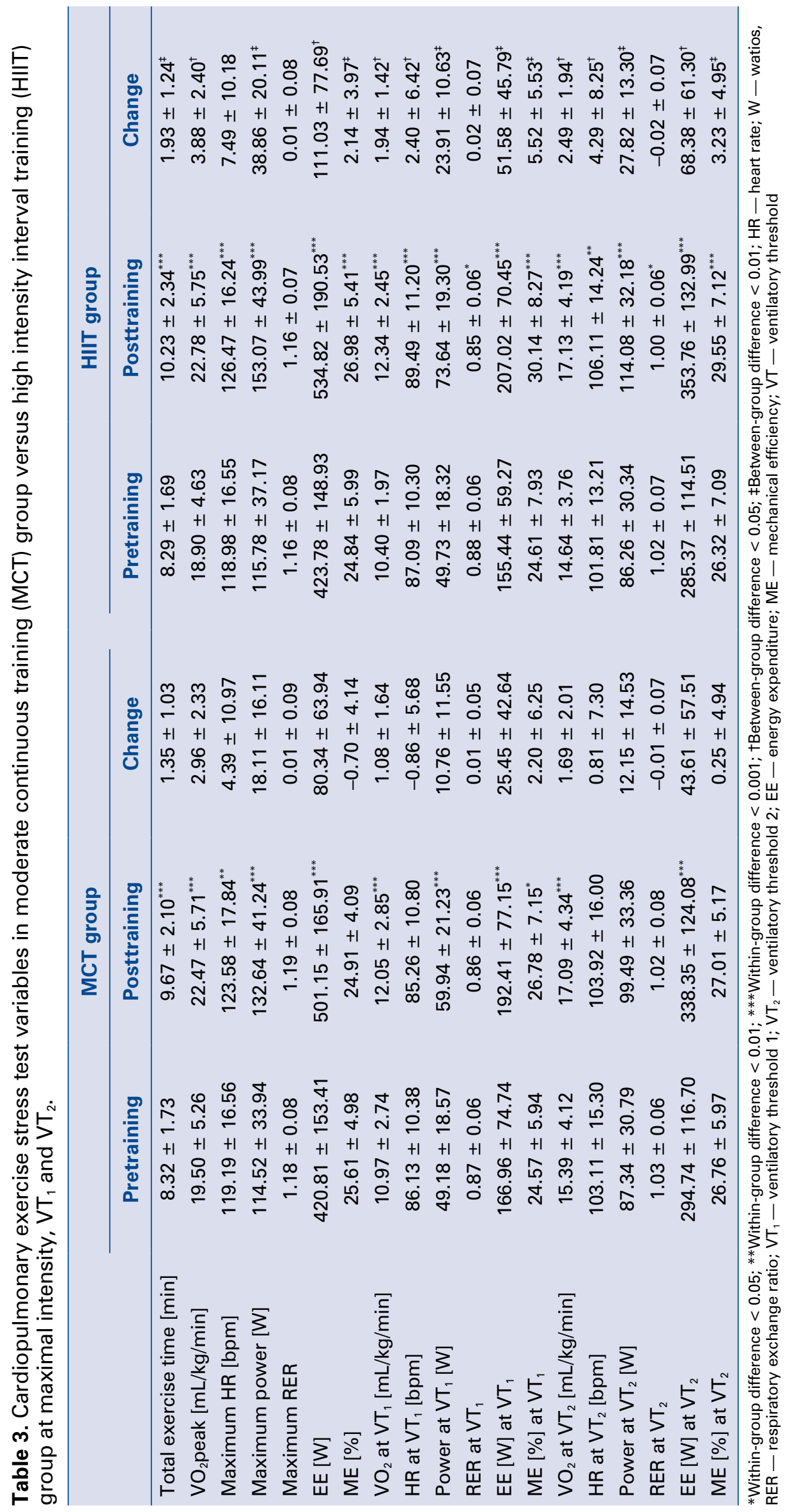


served in many patients with a cardiovascular pathology [1]. In this context, the improvement in ME (a lower cost of ATPs for the same muscular effort applied) is essentially determined by the improvement of ATP consumption from myosin-ATPase and noncontractile processes related to ion transport associated with the contraction-relaxation cycle (mainly calcium ATPase and to a lesser extent due to Na-K-ATPase). Therefore, any improvement of one of these processes would explain the fall in energy cost of contraction at any exercise intensity level (e.g. $\mathrm{VT}_{1}, \mathrm{VT}_{2}, \mathrm{VO}_{2}$ peak) [1].

The energy required to sustain a given bicycle workload has been previously shown to be correlated with body mass $[15,16]$. In the present study, bodyweight decreases in the same proportion in the two training groups during the intervention period, which rules out body mass as an influential factor in the observed modification of ME in the HIIT-group.

A lower $\mathrm{O}_{2}$ for the same production of power during the bicycle workload could be the result of: 1) A lower ATP cost of the muscular contraction for the same production of effort (an improvement in muscle contraction efficiency); and/or 2) A lower $\mathrm{VO}_{2}$ for the same level of ATP oxidative resynthesis (an improvement in mitochondrial efficiency). HIIT was able to increase $\mathrm{VO}_{2}$ peak, maximum load (Wmax) and ME to a greater extent, especially by improving the internal cell environment of the muscles active during exercise. However, some authors are of the opinion that the typical short-term adaptations to endurance training such as increased oxygen delivery [17], muscle capillarization and mitochondrial content [18], among others, have a limited impact on $\mathrm{ME}$, meaning that improvements in muscle motor function cannot be excluded as a key element in the improvement of ME.

Moreover, type II muscle fibres have been demonstrated to be substantially less efficient than type I fibres during cycling, as reflected by higher $\mathrm{VO}_{2}$ in performing exercise at a given power output [19]. Training in aerobic resistance, such as the one employed in the two groups of this study, especially reinforces the oxidative capacity of type I fibres, being able to sustain greater exercise intensity (greater levels of applied resistance). This fact would result in a greater ME.

In athletes HIIT improvement in "metabolic stability" (e.g. reduced changes in concentrations of muscle metabolites such as ADP, AMP, inosinemonophosphate, creatine, inorganic phosphate, and $\mathrm{H}^{+}$for a given ATP turnover) may be crucial to limit muscle fatigue, $\mathrm{VO}_{2}$ slow component, and ME impairment occurring at heavy and severe ex- ercise intensities, particularly through a decrease in the ATP use/power output ratio [20]. Although HIIT in coronary patients are of a less demanding nature from a metabolic point of view, the attainment of partial biochemical muscular adaptations which contribute to the improvement in "metabolic stability" may be speculated upon, and with it ME.

Mechanical inefficiency is mainly related to inactivity and it seems that the exercise intolerance promoted by the disease makes the patients less physically active, with a detraining effect on their peripheral muscles [21]. Lower ME indicates that more energy is consumed at a given work output. Therefore, individuals with lower ME values should be less efficient with respect to performance and may therefore be limited in terms of physical activity [2]. Consequently, an improvement in $\mathrm{ME}$ in patients with central limitation (cardiac), will contribute to an improvement in exercise capacity.

Different studies have shown greatest $\mathrm{VO}_{2}$ peak improvements in HIIT respect to continuous load training $[7,8,22]$. In the present research, both exercise programs significantly increased their $\mathrm{VO}_{2}$ peak, with a greater increase in the HIIT-group (difference between group: $\mathrm{p}<0.05$ ).

In line with the increase of $\mathrm{VO}_{2}$ peak, the maximum load reached increased significantly more in the HIIT-group $(\mathrm{p}<0.001)$, reflecting an improvement in the base-acid balance with peak loads.

The two groups of this study improved $\mathrm{VO}_{2}$ and the load (W) associated with $\mathrm{VT}_{1}$ and $\mathrm{VT}_{2}$, with greater improvements in HIIT. Similar results were found in other research studies [23, 24], however other authors have not observed differences associated to the modality of training $[7,8,25,26]$. While in research conducted by Moholdt and Rognmo the different protocols used may justify the lack of concordance in the results, in previous studies $[7,8]$, in which a trend for a greater improvement was found in $\mathrm{VO}_{2}$ and $\mathrm{W}$ associated with $\mathrm{VT}_{1}$, the greater number of patients included in the study meant that the trend had a statistical significance. Physiological variables associated with $\mathrm{VT}_{2}$ were observed - not an usual occurrence in clinical trials with cardiac patients. HIIT constitutes a training method with a clear objective of improvement inoxidative or aerobic status, but on attaining intensities greater than $\mathrm{VT}_{2}$, it significantly improves the glycolytic and lactate clearance processes.

Focus on $\mathrm{HR}$ related to $\mathrm{VT}_{1}$ and $\mathrm{VT}_{2}$, this factor only increased in the HIIT-group, reflecting peripheral metabolic adaptations that allow for sustaining a greater workload. The same results were observed previously [8] suggesting that the 
HR associated with ventilatory thresholds are perhaps not a valid variable reflecting an adaptation to exercise.

Additionally, HIIT seems to be a safe exercise modality and did not differ in frequency or magnitude of cardiovascular adverse events during exercise training as compared with MCT, as was shown previously [7].

\section{Conclusions}

The results of the present research show that the application of HIIT to patients with chronic ischemic heart disease of low risk resulted in a greater improvement in $\mathrm{VO}_{2}$ peak and in $\mathrm{ME}$ at $\mathrm{VT}_{1}$, than when MCT was applied. Moreover, only the application of HIIT brought about a significant increase in $\mathrm{ME}$ at $\mathrm{VT}_{2}$ and at $\mathrm{VO}_{2}$ peak.

\section{Conflict of interest: None declared}

\section{References}

1. Layec G, Haseler LJ, Hoff J, et al. Evidence that a higher ATP cost of muscular contraction contributes to the lower mechanical efficiency associated with COPD: preliminary findings. Am J Physiol Regul Integr Comp Physiol. 2011; 300(5): R1142-R1147, doi: 10.1152/ajpregu.00835.2010, indexed in Pubmed: 21307358.

2. Jabbour G, Iancu HD. Mechanical efficiency improvement in relation to metabolic changes in sedentary obese adults. BMJ Open Sport Exerc Med. 2015; 1(1): e000044, doi: 10.1136/bmjsem-2015-000044, indexed in Pubmed: 27900132.

3. Jabbour G, Iancu HD, Mauriège P, et al. High-intensity interval training improves performance in young and older individuals by increasing mechanical efficiency. Physiol Rep. 2017; 5(7): e13232, doi: 10.14814/phy2.13232, indexed in Pubmed: 28381445.

4. Anderson L, Thompson DR, Oldridge N, et al. Exercise-based cardiac rehabilitation for coronary heart disease. Cochrane Database Syst Rev. 2016; 67(1): CD001800, doi: 10.1002/14651858. CD001800.pub3, indexed in Pubmed: 26730878.

5. Hambrecht R, Niebauer J, Fiehn E, et al. Physical training in patients with stable chronic heart failure: effects on cardiorespiratory fitness and ultrastructural abnormalities of leg muscles. J Am Coll Cardiol. 1995; 25(6): 1239-1249, doi: 10.1016/07351097(94)00568-B, indexed in Pubmed: 7722116.

6. Ito S, Mizoguchi T, Saeki T. Review of High-intensity Interval Training in Cardiac Rehabilitation. Intern Med. 2016; 55(17): 2329-2336, doi: 10.2169/internalmedicine.55.6068, indexed in Pubmed: 27580530.

7. Villelabeitia-Jaureguizar K, Vicente-Campos D, Senen AB, et al. Effects of high-intensity interval versus continuous exercise training on post-exercise heart rate recovery in coronary heartdisease patients. Int J Cardiol. 2017; 244: 17-23, doi: 10.1016/j. ijcard.2017.06.067, indexed in Pubmed: 28648356.

8. Jaureguizar KV, Vicente-Campos D, Bautista LR, et al. Effect of high-intensity interval versus continuous exercise training on functional capacity and quality of life in patients with coronary artery disease: a RANDOMIZED CLINICAL TRIAL. J Cardiopulm Rehabil Prev. 2016; 36(2): 96-105, doi: 10.1097/ /HCR.0000000000000156, indexed in Pubmed: 26872000.

9. Kyröläinen H, Avela J, McBride JM, et al. Effects of power training on mechanical efficiency in jumping. Eur J Appl Physiol. 2004; 91(2-3): 155-159, doi: 10.1007/s00421-003-0934-z, indexed in Pubmed: 14530982.
10. Gillen JB, Gibala MJ. Is high-intensity interval training a timeefficient exercise strategy to improve health and fitness? Appl Physiol Nutr Metab. 2014; 39(3): 409-412, doi: 10.1139/apnm2013-0187, indexed in Pubmed: 24552392.

11. Skinner JS, McLellan TM, McLellan TH. The transition from aerobic to anaerobic metabolism. Res Q Exerc Sport. 1980; 51(1): 234-248, doi: 10.1080/02701367.1980.10609285, indexed in Pubmed: 7394286.

12. Meyer K, Samek L, Schwaibold M, et al. Interval training in patients with severe chronic heart failure: analysis and recommendations for exercise procedures. Med Sci Sports Exerc. 1997; 29(3): 306-312, indexed in Pubmed: 9139168.

13. Garby L, Astrup A. The relationship between the respiratory quotient and the energy equivalent of oxygen during simultaneous glucose and lipid oxidation and lipogenesis. Acta Physiol Scand. 1987; 129(3): 443-444, indexed in Pubmed: 3577829.

14. Lafortuna CL, Proietti M, Agosti F, et al. The energy cost of cycling in young obese women. Eur J Appl Physiol. 2006; 97(1): 16-25, doi: 10.1007/s00421-006-0137-5, indexed in Pubmed: 16463044 .

15. Berry MJ, Storsteen JA, Woodard CM. Effects of body mass on exercise efficiency and VO2 during steady-state cycling. Med Sci Sports Exerc. 1993; 25(9): 1031-1037, indexed in Pubmed: 8231771.

16. Cotes JE. Relationships of oxygen consumption, ventilation and cardiac frequency to body weight during standardized submaximal exercise in normal subjects. Ergonomics. 1969; 12(3): 415-427, doi: 10.1080/00140136908931065, indexed in Pubmed: 5345650.

17. Bonne TC, Doucende G, Flück D, et al. Phlebotomy eliminates the maximal cardiac output response to six weeks of exercise training. Am J Physiol Regul Integr Comp Physiol. 2014; 306(10): R752-R760, doi: 10.1152/ajpregu.00028.2014, indexed in Pubmed: 24622974.

18. Hoppeler H, Howald H, Conley K, et al. Endurance training in humans: aerobic capacity and structure of skeletal muscle. J Appl Physiol (1985). 1985; 59(2): 320-327, doi: 10.1152/jappl.1985.59.2.320, indexed in Pubmed: 4030584.

19. Coyle EF, Sidossis LS, Horowitz JF, et al. Cycling efficiency is related to the percentage of type I muscle fibers. Med Sci Sports Exerc. 1992; 24(7): 782-788, indexed in Pubmed: 1501563.

20. Grassi B, Rossiter HB, Zoladz JA. Skeletal muscle fatigue and decreased efficiency: two sides of the same coin? Exerc Sport Sci Rev. 2015; 43(2): 75-83, doi: 10.1249/JES.0000000000000043, indexed in Pubmed: 25688762.

21. Høydal K, Helgerud J, Karlsen T, et al. Patients with coronary artery- or chronic obstructive pulmonary disease walk with mechanical inefficiency. Scand Cardiovasc J. 2009; 41(6): 405-410, doi: 10.1080/14017430701601636.

22. Warburton DER, McKenzie DC, Haykowsky MJ, et al. Effectiveness of high-intensity interval training for the rehabilitation of patients with coronary artery disease. Am J Cardiol. 2005; 95(9): 1080-1084, doi: 10.1016/j.amjcard.2004.12.063, indexed in Pubmed: 15842976.

23. Currie KD, Dubberley JB, McKelvie RS, et al. Low-volume, high-intensity interval training in patients with CAD. Med Sci Sports Exerc. 2013; 45(8): 1436-1442, doi: 10.1249/ MSS.0b013e31828bbbd4, indexed in Pubmed: 23470301.

24. Keteyian SJ, Hibner BA, Bronsteen K, et al. Greater improvement in cardiorespiratory fitness using higher-intensity interval training in the standard cardiac rehabilitation setting. J Cardiopulm Rehabil Prev. 2014; 34(2): 98-105, doi: 10.1097/ /HCR.0000000000000049, indexed in Pubmed: 24531203.

25. Rognmo Ø, Moholdt T, Bakken H, et al. Cardiovascular risk of high- versus moderate-intensity aerobic exercise in coronary heart disease patients. Circulation. 2012; 126(12): 1436-1440, doi: 10.1161/CIRCULATIONAHA.112.123117, indexed in Pubmed: 22879367.

26. Moholdt T, Aamot IL, Granøien I, et al. Aerobic interval training increases peak oxygen uptake more than usual care exercise training in myocardial infarction patients: a randomized controlled study. Clin Rehabil. 2012; 26(1): 33-44, doi: 10.1177/0269215511405229, indexed in Pubmed: 21937520. 